\author{
This is the Author Original Manuscript of an article published by Taylor \& \\ Francis in International Journal on Media Management on May 11 2017, available \\ online: http://www.tandfonline.com/doi/full/10.1080/14241277.2017.1298112
}

\title{
Crowdfunding Japanese Commercial Animation: Collective Financing Experiences in Anime
}

This paper offers an exploration of the incipient development of crowdfunding anime projects for short and medium-length films. Japanese commercial animation is characterised by the support of a strong production industry that primarily targets local audiences through cross-media projects, developed in synergy with other cultural sectors (such as the publishing industry, record labels or video game developers). The growing acceptance of anime in markets around the world has strengthened it as one of the most well-known forms of Japanese popular culture and has also resulted in changes to some of the dominant dynamics of its production to adapt to technological innovations. One of these changes has been the rise of crowdfunding, an increasingly popular form of financing involving the patronage of fans from all corners of the world who want to participate in these audiovisual projects. This paper analyses the response to some of the more popular initiatives from a historiographical perspective on the production and reception of commercial animation and the main theories related to the relationship between the hyperactive nature of Japanese fandom and collective financing. The conclusions include the confirmation of the increasing receptiveness to anime crowdfunding among potential sponsors - especially among fans based outside Japan on platforms with a global reach, such as Kickstarter-and a consideration of the transformative potential of this phenomenon for a precarious industry and its usefulness as a tool for exploring the viability of the production and distribution of projects by animation studios. 


\section{Introduction}

Anime, or Japanese commercial animation, has achieved its highest level of global fame in the first years of the new millennium, thanks largely to its acceptance as an emerging form of expression in Western cultural markets. Although its presence on television programming schedules around the world has been practically constant since its origins (e.g. Astro Boy was distributed by NBC Enterprises in the United States as early as 1963; Clements, 2013: 123), it was not until the more recent explosion of industry accolades, such as the Academy Award for Best Animated Feature in 2003 given to Spirited Away (Sen to Chihiro no Kamikakushi, H. Mayazaki, Studio Ghibli, 2001), that Western distribution companies began to focus on licensing anime film features and television series for their markets.

Concurrent with the growing interest in anime among critics and audiences, academic publications from the emergent field of Anime Studies have demystified the idealised image of anime as a prestigious cultural product in the West. ${ }^{1}$ Questioning the ennobled image of Japanese animation, recent scholarly inquiries have explored the back room of animation studios and have helped to construct an overview of the industry that highlights the precarious nature of its working conditions (see Mōri, 2011), a surprising fact if we consider that Japanese animation is one of the most prolific cultural industries on the planet. For instance, several researchers have deconstructed the common generalisation that "anime $=$ Studio Ghibli" and have revealed that the production model of this acclaimed studio, far from being representative of the rest of the Japanese animation industry, is rather an oddity: Ghibli's business model is based on huge investments in permanent staff (from two to three years per project) to develop monumental feature films suitable for all audiences. Thus, the sustainability of this

\footnotetext{
${ }^{1}$ This is why the Japanese government has identified it, together with manga, J-Pop, video games and gastronomy, as a cultural ambassador of "Cool Japan” (Galbraith, 2009: 49-51).
} 
model depends greatly on the box office response to produce the resources needed for subsequent projects (Montero Plata, 2012: 72). Unlike the artistic manga eiga (manga films; LaMarre, 2008: 125) of which Hayao Miyazaki is such a notable exponent, the anime genre is still predominantly a television product, a continuation of the style established by Mushi Pro's Astro Boy — traceable in turn to the Hanna-Barbera cartoons in its use of limited animation. The existence of anime depends crucially on its promotional usefulness as one of the strategies developed when production committees (seisaku iinkai, Steinberg, 2012: 172) involved in the media mix (the cross-media alliances between different actors of Japanese cultural industries, including publishers, animation studios, game developers, music labels, and merchandisers; Ito, 2004) agree to the commercial exploitation of a successful manga (the case of Astro Boy as studied extensively by Steinberg in 2006, 2009, 2012 and 2013), video game (Pokémon; Tobin, 2004) or character design (Hello Kitty; Yano, 2013). Thus, the animation studios responsible for the adaptation of these narrative universes to television series are generally no more than an important cog in the machine constructed by the production committees, one-time alliances driven by the aim of minimising risks and sharing losses in the creation of new media mixes.

The historically mechanised routines of commercial animation in professional studios (Sito, 2006) are accelerated by the extraordinarily prolific nature of Japanese animation, which, for example, released 44 new television series between January and March 2016 (Anime News Network, 2016a). Consequently, the working conditions for animators and artistic teams are compromised by their precariousness, and aggravated by the extreme demands of television schedules. Time constraints on production have also resulted in a high reliance on the outsourcing of some tasks, an activity that has eliminated the traditional training of younger animators due to the "Byzantine hierarchy 
of assistants: clean-up people, assistant animators, in-betweeners" (Furniss, 2009: 191192), since a great deal of those basic tasks are entrusted to foreign animation studios in other parts of East Asia (Poitras, 2008: 63).

On the periphery of commercial anime we can find a wide variety of artists and professionals who, either because of their involvement in more experimental endeavours or because they are veterans who grew tired of the demands of the system, have been able to develop a whole series of personal projects despite the uncertainties and risks inseparable from entrepreneurship (Compaine \& Hoag, 2012: 29) thanks to the efficient fund raising and tighter creative control implied in crowdfunding processes (Gerber \& Hui, 2013: 8-12).

\section{Theoretical Framework and Methodology}

Based on previous experiences in microfinancing and crowdsourcing, crowdfunding is a novel financing method that allows individuals to contribute to the funding of projects of any kind through small monetary contributions, either in the form of direct donations or, more commonly, in exchange for some degree of involvement in the result, such as a share in the profit.

Mollick lists four principal reasons for the success of a crowdfunding project: the quality of the project, the skill in the use of social networks, the geographic reach and the type of target audiences (2014: 2). In reward-based crowdfunding, its most common modality (Burtch, Goose \& Wattal, 2013: 18), patrons receive a reward for their contribution to the project, which may come in the form of recognition in the credits of an audio-visual work, meeting with the creators of the project or even being able to collaborate in the creative process. The type of reward offered is normally linked to the amount of the contribution, with the campaign founder establishing 
predetermined contribution levels with associated awards for each level. In this modality of crowdfunding, backers can be treated as the first consumers through privileged access to the results and may also be offered a better price for the final product or other benefits.

The emergence of crowdfunding for audio-visual projects is related to both the drying up of cultural and commercial enterprises and the few regulatory boundaries for arts and entertainment ventures (Bruton, Khavul, Siegel \& Wright, 2015: 12). The advent of crowdfunding has changed some of the dominant production dynamics of animation projects, adapting them to technological and social innovations. As pointed out by Davidson and Poor, "[b]y allowing the broad public to directly fund cultural projects, crowdfunding has the potential to restructure the culture industries value chain and disintermediate traditional gatekeepers such as movie studios or publishers" (2014: 290). Indeed, crowdfunding projects enable small-scale entrepreneurs to make philanthropic donations which, filtered through intermediary platforms for participative funding, ultimately offer them a point of entry into the previously inaccessible production systems of the capitalist economy (Hamilton, 2014: 497-498). These projectlaunching platforms function as a kind of competition in which only the successful proposals are the ones to receive the capital offered by the backers. Thus, the support provided by backers is not received as a donation, but as a transaction in exchange for the different rewards promised at each campaign contribution level. Ultimately, the process is as rigid as a regular transaction because the degree of participation is tied to the contribution level. In this way, far from transforming the project into a collective process, crowdfunding is really the collective financing of a product whose creative capital is non-negotiable from the start. 
Beyond financing the product itself, the integration of crowdfunding into the routines of commercial producers can be useful as a form of market research:

crowdfunding has been used by founders to demonstrate demand for a proposed product, which can lead to funding from more traditional sources. [...] Conversely, a lack of demand makes it easy for founders to "fail quickly" if they see little interest in a project, without the need to invest additional capital or effort (Mollick, 2014: 3).

The emergence of crowdfunding can be analysed as a major contribution to the incorporation of new practices into the field of audio-visual production, precisely because it is "a space to foster marginalized talents and projects that, either by choice or necessity, exist outside of mainstream media industries" (Scott, 2015: 168). The case of Japanese animation presents an additional dimension because of the intensity of the relationship between fans and the products of commercial popular culture that redound to the main motivations for crowdfunding supporters as outlined by Gerber \& Hui: being part of a community, supporting a cause to help others and collecting rewards (2013: 12-13). Otaku communities around the world have had a transformative effect on the traditionally unidirectional relationship between producers and consumers. Activities such as anime fansubbing (Díaz Cintas \& Muñoz Sánchez, 2006), manga escalations (Brenner, 2007: 205-206) or the inventive dojinshi (Thorn, 2004: 170), all of which were initially viewed as unlawful copyright infringements, have come to be understood by copyright holders and distributors as extensions of one of the paradigmatic expressions of the otaku subculture observed by sociologist Hiroki Azuma, referred to as the niji-sosaku trend (Mōri, 2006: 186): user-generated content, generally with erotic or comical revisions of characters and fictional universes of previous manga or anime (Azuma, 2009: 26). They have also come to be seen as 
generally useful markers for identifying a demand in a given territory and working out how to satisfy it. For these reasons, anime crowdfunding represents a prime example of "fan-ancing" (Scott, 2015) due to a higher level of commitment by backers to the projects they support, projects with which they maintain a special (thematic and authorial) affinity: "Building a community that supports the entrepreneur is a critical ingredient for crowdfunding to be more profitable than traditional funding" (Belleflamme, Lambert and Schwienbacher, 2014: 587).

Based on a historiographical perspective on the production and reception of commercial animation and its main contributions to a theorisation of crowdfunding in relation to the hyperactive nature of Japanese fandom, this article presents an analysis of the responses to crowdfunding in the Japanese animation industry using the short film Kick-Heart (M. Yuasa, Production I.G, 2013) as a case study. The analysis of this project and of the design of four other anime crowdfunding campaigns confirms the growing acceptance of this type of funding among potential backers-especially those based outside Japan on global-reach platforms such as Kickstarter-and highlights the potentially transformative capacity of these successful initiatives and their usefulness as a tool for animation studios to explore the viability of an anime project prior to investing fully in its production or international distribution.

\section{Kickstarting Anime: Kick-Heart}

Masaaki Yuasa is one of the most renowned young creators in Japanese commercial animation on the international scene. His style, divorced from the conventions of traditional anime, has given him a prominent position among the new generation of talents being sought out by animation studios. Yuasa has directed several 
projects for Studio $4^{\circ} \mathrm{C}$ (the feature film Mind Game in 2004 and the short film Happy Machine in 2008), for Madhouse (the television series Kemonozume in 2006, Kaiba in 2008 and The Tatami Galaxy in 2010) and for Tatsunoko Productions (the television series Ping Pong in 2014). Like earlier anime filmmakers (such as Katsuhiro Otomo, Mamoru Oshii or Satoshi Kon), Yuasa's oeuvre has attracted the interest of international audiences thanks to its inclusion in animation festivals around the world. In addition to numerous accolades, a clear sign of the international recognition of Yuasa's work was his collaboration as director and screenwriter of the episode "Food Chain" in one of the most popular animated series of the $21^{\text {st }}$ century: Adventure Time (P. Ward, Cartoon Network, 2010-). Encouraged by the studio Production I.G. to pursue any of the projects he was working on, Yuasa agreed to launch a crowdfunding campaign for a short animated film through Kickstarter, the world's biggest online crowdfunding platform.

Through their all or nothing funding model — which requires all funds to be sent back to backers if the goal is not reached (Gerber and Hui, 2013: 4) — this platform has facilitated the collection of around $\$ 301,97$ million to successfully fund 21.979 "Film and video" projects with a success rate of $37,19 \%$ (Kickstarter, 2016). Among them we find a wide variety of animation endeavours (see Table 1 for a detailed outlook): from ambitious series projects by established powerhouses of animation around the world such as Frederator Studio or Aardman Animations to independent feature films (such as Charlie Kaufman's Anomalisa or Lopez's Hullabaloo Steampunk) and adaptations of highly popular webcomics (Cyanide and Happiness and Nichtlustig) and video games (Wakfu and Implosion).

The campaign, under the title of "Masaaki Yuasa's 'Kick-Heart"' invoked the filmmaker's status as an auteur to lure backers from around the world. The online 
presentation included brief interviews with Yuasa and his artistic staff, as well as colour drafts of the storyboard, character designs and gorgeous illustrations presenting the project and the rewards offered to contributors. As a crucial part of the campaign, regular updates on the state of the funding and the production development were also posted on the project profiles created in Facebook (1137 followers), Twitter (1433 followers) and Tumblr. This is a decisive issue in the context of networking participation and collective intelligence communities. As Salo, Lankinen \& Mäntymäki suggest in their exploration of independent music marketing (2013: 26) the reinforcement of social identity and affinity of both individual and group through the active participation across user-generated content, and two-way interaction between the members are important motives for consumers for using social media.

Supported by 3,232 backers, the campaign raised a total of $\$ 201,164$ (well over the initial goal of $\$ 150,000)$ between the $1^{\text {st }}$ and $31^{\text {st }}$ of October 2012. The rewards ranged from computer wallpapers, high definition copies of the film, original sketches, key frames, storyboards, soundtracks and even a wrestling soiree in Tokyo in the company of Yuasa and his production team (Kick-Heart Project, 2012). The average individual investment in the project was $\$ 62.24$; the largest proportion of patrons $(710$ backers, $22 \%$ of the total) chose the reward offered for contributions in the $\$ 15-29$ threshold: a pack that included a digital copy of the short, a B2 poster, a postcard and wallpaper. Its premiere party in Tokyo on 26 May 2013 was a costume party (all attendees were required to wear a mask) featuring a live performance by the soundtrack producer, Oorutaichi, and a live painting session by Yuasa.

The resulting 12-minute short follows the same creative path as Yuasa's previous works, in the opposite direction to conventional anime, closer to the spirit of the original cartoon tradition (from the short film format to the timing of the gags) than 
the duller television variety. Although, like traditional anime, Kick-Heart uses limited animation, its use is closer to the experimental innovation of the short films developed by UPA in films like Rooty Toot Toot (J. Hubley, 1951) than the mere corner-cutting budget strategy that typified its use in the Hanna-Barbera series. The opening credit sequence (designed by French animator Aymeric Kevin, who was also responsible for the background art in Kick-Heart) can be seen as clear proof of the different aesthetic from which the project took its inspiration, using sketched watercolour animation edited over vaudeville music. The comic plot covers two days in the life of a masochistic vale tudo fighter-who fights for money to raise funds for the orphanage where he grew up - and his fight with a sadistic masked woman, who eventually is revealed to be the new nun working at the orphanage. The film abounds with scatological references, clear allusions to BDSM and pornography and oneiric visions, all packaged in an eclectic surrealist style inspired by seminal works of this kind, such as Yellow Submarine (Dunning, 1968), Tex Avery's hilarious comedies, Batman: The Animated Series (Warner Bros. Animation 1992-1995), and classic Japanese animation like Tiger Mask (T. Tamiya, Toei Animation, 1969-1971). All these recognisable influences reveal a sensibility very different from commercial anime, more commonly found in the genres of science-fiction and fantasy. The non-conventional planning, rich in off-centred and abnormal framings, is reinforced by the use of large, monocoloured shapes. The aggressive character design (employed as much to sexualise the bodies as to exploit the grotesque aspects of wrestling) and the static backgrounds bear no resemblance to the aspiring photorealism of some recent television anime.

In the making-of of the film (Eunyong Choi, 2014), Yuasa confesses that the need to deliver a quality final product after the support received by the backers imposed a unique sense of obligation: "It was almost a pressure, but a grateful one. Last year 
wasn't the busiest one for me, so this experience made me happy and motivated. It made me feel that I can still survive in this industry." Yuasa's observation underscores the qualities of crowdfunding as a viable way for pursuing anime projects with different rhythms to the time constraints of commercial circuits.

\section{Beyond Kick-Heart: Following Anime Crowdfunding Projects}

Before concluding, it is worth commenting briefly here on other significant crowdfunding anime projects.

The first is Little Witch Academia: The Enchanted Parade (Y. Yoshinari, Trigger, 2015), which was notable for drawing on both crowdfunding and public investment for its production budget. It was the sequel to a film that formed part of the Young Animator Training Project (Wakate Animètā Ikusei Purojekuto), an initiative promoted initially by the Japanese Association of Animation Creators (JAniCA), and since 2015 by the Association of Japanese Animation (AJA), and that has been funded since 2011 by the Japanese government's Agency of Cultural Affairs in response to a structural problem in the industry: insufficient promotion of new filmmakers. The series of short films produced under the project's different phases-Project A (2011), Anime Mirai (2012-2015) and Anime Tamago (2016) — have also been supported by both emerging and consolidated studios such as Madhouse, Gonzo, Production I.G, Studio $4^{\circ} \mathrm{C}$ and Trigger. This last studio was the promoter of the first Little Witch Academia film (Y. Yoshinari, 2013), and also of the Kickstarter campaign to cover the cost of producing around twenty additional minutes for its sequel. In view of an impressive response from backers, with $\$ 150,000$ raised in just five hours (Anime News Network, 2013), the production of a documentary and audio-commentary was added to the budget and new rewards were offered for the project's different contribution levels (still 
frames, art books, signed scripts and even a guided tour through the studio). A total of 7,938 patrons helped to reach the upgraded goal of $\$ 500,000$, an extraordinary result which, together with the warm welcome the film has received in Japanese theatres, has led its creators from contemplating the possibility of a larger project for the future (Little Witch Academia Project, 2013) to the fulfilment of an animated television series to premiere on January 2017 and licensed by Netflix for streaming.

The development of Under the Dog (M. Ando, Kinema Citrus) deserves special attention as a paradigmatic example of two situations that are typical of crowdfunding projects. Firstly, it was a project rescued from the drawer after being discarded in the 90 s, and creatively reactivated with the involvement of renowned professionals in the field thanks to an extremely successful crowdfunding campaign to produce a highprofile pilot for an animated television series $(\$ 878,028$; Under the Dog Project, 2014). And secondly, the development of the project has faced severe problems arising from creative differences after the campaign-Creative Intelligence Arts, the company in charge of production, abandoned the project, leaving the task to an expressly assembled supervising team (Mentat Studios LLC), in whose ranks we can find one key actor in contemporary anime, director Koji Morimoto - and constant changes in the artistic staff have led to external intervention to restructure project resources, due to various difficulties associated with erroneous calculations of the costs of the rewards offered to backers (Anime News Network, 2015b). All these factors delayed the release of the film until August 2016. Nevertheless, Under the Dog can be considered a successful endeavour, given that anime initiatives launched through Kickstarter do not always achieve their funding objectives. For instance, a project for a children's miniseries titled Chuya-Den - The Night and Day Chronicles, launched by the Japanese studio WAO World, did not achieve its $\$ 100,000$ goal for the production of a ten-minute pilot 
episode (Project Chuya-Den, 2015), perhaps because its thematic content strayed too far from traditional otaku themes. In contrast, Under the Dog clearly reflects the aesthetic of the most famous anime titles, such as Akira (K. Otomo, Tokyo Movie Shinsha, 1988) or Ghost in the Shell (M. Oshii, Production I.G, 1995).

Finally, not based on Kickstarter but on the Japanese crowdfunding platform Makuake, In This Corner of the World (Kono Sekai no Katasumi ni, S. Katabuchi, MAPPA) received support from 3,347 backers on Makuake (Kono sekai no katasumi ni, 2015), which helped to practically double the initial fundraising goal of 20 million yen. After the premiere of the film on October 2016, another crowdfunding campaign was raised in order to gather new resources to cover the overseas trip of director Sunao Katabuchi for the international screenings of the film (Anime News Network, 2016b). In this case, the novelty lies in the application of the production committee model outside the commercial circuit, as it is an adaptation of a serialised manga from a major magazine in the Japanese publishing industry, but in partnership with a new animation studio. Indeed, the involvement of the MAPPA studio could be understood as an audacious step — related to one of the key motivations for commercial creators to start a crowdfunding process: to learn and/or improve new fundraising skills (Gerber and Hui, 2013: 13) - towards the new possibilities of animation production, especially if we consider that the former chief producer for Madhouse, Masao Maruyama, founded the studio. Crowdfunding production is thus changing the formerly immutable production routines of the Japanese animation industry. 



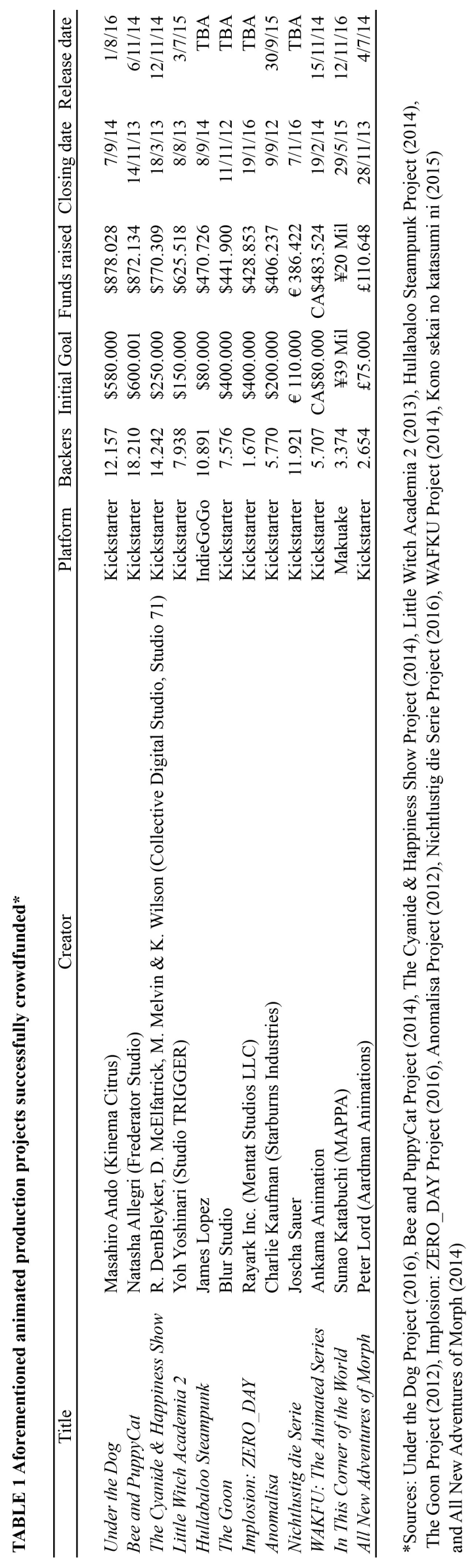




\section{Conclusions}

The emergence of crowdfunding as a source of alternative funding for Japanese commercial animation is a reflection of the variety of sectors involved in the production of culture in the collective intelligence environment (Bonabeau, 2009) where it represents "a potentially significant change for independent film as it shifts from a supply-led to a demand-led market" (Kehoe \& Mateer, 2015: 94). Its use as a form or preliminary market research could help Japanese animation studios to consolidate the production of their feature films or series, something that could result in both a change to the current duration of projects (especially the television series format of a single season of thirteen episodes) and a stimulus for international distribution in the event of a positive response from patrons outside Japan. As Mollick suggests:

crowdfunding potentially changes the nature of geography and association in new ventures. At least in part, crowdfunding reduces the importance of traditional geographic constraints, even as it potentially imposes new ones. Further, online social networks and communities increase in relevance in crowdfunding (2014: 14).

Finally, it is also worth noting Western initiatives to procure backers for the edition and distribution of classic anime that has been discontinued or was never made available outside of Japan, such as the recently shut down Anime Sols (2012-15), a streaming and crowdfunding platform resulting from an association between the studios Pierrot, Tezuka Production and Tatsunoko Productions (Anime News Network, 2015a). Focused strictly on the North American market, this initiative made DVD editions of anime titles owned by these studios available in the United States for the first time once the threshold costs established by the platform were met. The support this initiative provided for the production of the complete editions of Oniisama E... (O. Dezaki, 
Tezuka Pro, 1991-92), Mahō no Tenshi Creamy Mami (O. Kobayashi, Pierrot, 1983-84) and the partial edition of Black Jack (S. Kuwabara, Tezuka Pro, 2004-06) is testimony to the possibilities that crowdfunding can offer Japanese commercial animation beyond the stale consideration of these parallel channels as a threat to the total control exerted by conventional media producers (Mann, Mahnke \& Hess, 2012: 253).

Outside of the commercial industry, animators like Yuasa, whose narrative and artistic sensibilities differ from those imposed by the conventions of major mainstream projects, can use crowdfunding as a means of identifying potential niche markets for their aesthetic concerns, and of obtaining the resources necessary to realise projects that could be used as a means of introducing themselves at animation festivals around the world.

Despite the positive experiences outlined in this paper, it might still be too early to determine whether crowdfunding has a future as a useful means of funding anime projects. Although it is clear that a modest group of patrons can provide a boost for a creative project, the restrictions inherent to audio-visual production make total independence impossible, and thus crowdfunding needs to be supplemented by funding from major public or private investors. If we agree with C. W. Ceram's assessment that "in History, a process does not 'start' until it leads to a new productive phase" (qtd. in Bendazzi, 2003: 9), we should be attentive to the evolution of this incipient model of audiovisual production in the coming years, to determine its ultimate significance for the production of Japanese animation and contemporary popular culture.

\section{References}

All New Adventures of Morph Project (2014) All New Adventures of Morph from Aardman Animations. Retrieved 28 December 2016, from: 
https://www.kickstarter.com/projects/1961548517/all-new-adventures-of-morph-fromaardman-animation

Anime News Network (2013). Trigger's Little Witch Academia 2 Meets Kickstarter Goal. Anime New Network. Retrieved 19 December 2016, from http://www.animenewsnetwork.com/news/2013-07-09/trigger-little-witch-academia-2$\underline{\text { meets-kickstarter-goal }}$

Anime News Network (2015a). Anime Sols Streaming/Crowdfunding Service to Close on May 1. Retrieved 20 December 2016, from http://www.animenewsnetwork.com/news/2015-04-01/anime-sols-streamingcrowdfunding-service-to-close-on-may-1/.86607

Anime News Network (2015b). Under the Dog Anime Project Streams New $\begin{array}{lllll}\text { Trailer. } & \text { Retrieved } & 23 & \text { December } & \text { 2016, }\end{array}$ http://www.animenewsnetwork.com/news/2015-09-07/under-the-dog-anime-projectstreams-new-trailer/.92635

Anime News Network (2016a). Upcoming TV. Retrieved 28 October 2016, http://www.animenewsnetwork.com/encyclopedia/anime/upcoming/tv

Anime News Network (2016b). In This Corner of the World Meets Crowdfunding Goal in 1 Day to Send Director Overseas. Retrieved 28 December 2016, from $\quad$ http://www.animenewsnetwork.com/news/2016-11-24/in-this-corner-of-the$\underline{\text { world-meets-crowdfunding-goal-in-1-day-to-send-director-overseas/.109100 }}$

Anomalisa Project (2012) Charlie Kaufman's Anomalisa. Retrieved 23 December 2016, from https:/www.kickstarter.com/projects/anomalisa/charliekaufmans-anomalisa?lang $=\mathrm{es}$

Azuma, H. (2009). Otaku: Japan's database animals. Minneapolis: University of Minnesota Press. 
Bee and PuppyCat Project (2013). Bee and PuppyCat. Retrieved 28 December 2016, from https://www.kickstarter.com/projects/frederator/bee-and-puppycat-the-series

Belleflamme, P., Lambert, T., \& Schwienbacher, A., (2014). Crowdfunding: Tapping the right crowd. Journal of Business Venturing, 29(5), 585-609.

Bendazzi, G. (2003). Cartoons: 110 años de cine de animación [Cartoons. 110 Years of Animation Film]. Madrid: Ocho y Medio.

Bonabeu, E., (2009). Decisions 2.0: the Power of Collective Intelligence. MIT Sloan Management Review, 50(2), 45-52.

Brenner, R.E. (2007). Understanding Manga and Anime. Westport: Libraries Unlimited.

Bruton, G., Khavul, S., Siegel, D. \& Wright, M., (2015). New Financial Alternatives in Seeding Entrepreneurship: Microfinance, Crowdfunding, and Peer-toPeer Innovations. Entrepreneurship Theory and Practice, 39(1), 9-26.

Burtch, G., Ghose, A., Wattal, S., (2015). An Empirical Examination of the Antecedents and Consequences of Contribution Patterns in Crowd-Funded Markets. Information Systems Research, 24(3), 499-519.

Chuya-Den Project (2015). CHUYA-DEN Campaign. Retrieved from https://www.kickstarter.com/projects/1287579779/chuya-den-the-night-and-daychronicles?ref=video

Clements, J. (2013). Anime: A History. London: Palgrave Macmillan.

Compaine, B. \& Hoag, A., (2012). Factors Supporting and Hindering New Entry in Media Markets: A Study of Media Entrepreneurs. International Journal of Media Management, 14(1), 27-49. 
Davidson, R. \& Poor, N., (2014). The Barriers Facing Artists' Use Of Crowdfunding Platforms: Personality, Emotional Labor, And Going To The Well One Too Many Times. New Media \& Society, 17(2), 289-307.

Díaz Cintas, J. \& Muñoz Sánchez, P., (2006). Fansubs: Audiovisual Translation in an Amateur Environment. The Journal of Specialised Translation, 6, 37-52.

Furniss, M. (2009). Animation: Art. Sydney: John Libbey.

Galbraith, P.W. (2009). The Otaku Encyclopedia: An Insider's Guide To The Subculture Of Cool Japan. New York: Kodansha International.

Gerber, E. \& Hui, J., (2013). Crowdfunding: Motivations and Deterrents for Participation. ACM Transaction on Computer-Human Interaction, 20(6), 1-32.

Hamilton, J.F., (2014). Historical forms of user production. Media, Culture \& Society, 36(4), 491-507.

Hullabaloo Steampunk animated film Project (2014) Hullabaloo Steampunk $\begin{array}{llll}\text { Project. } & \text { Retrieved } & \text { December } & \text { 2016, }\end{array}$ https://www.indiegogo.com/projects/hullabaloo-steampunk-animated-film\#/ Implosion: ZERO_DAY Project (2016). Implosion: ZERO_DAY. Retrieved 23 December 2016, from https://www.kickstarter.com/projects/774031583/implosion-zeroday/posts/1726065

Ito, M., (2004). Technologies of the childhood imagination: Media mixes, hypersociality, and recombinant cultural form. Items and Issues, 4(4), 31-34.

Kehoe, K. \& Mateer, J., (2015). The Impact of Digital Technology on the Distribution Value Chain Model of Independent Feature Films in the UK. International Journal on Media Management, 17(2), 93-108. 
Kick-Heart Project (2012). Campaign Description. Retrieved 23 November 2016, from https://www.kickstarter.com/projects/production-ig/masaaki-yuasas-kickheart/description

Kickstarter (2016). Stats. Retrieved 28 December 2016, from https://www.kickstarter.com/help/stats

Kono sekai no katasumi ni (2015). Retrieved 15 October 2016, from https://www.makuake.com/project/konosekai/

LaMarre, T. (2008). Animación limitada-completa. In Sánchez Navarro, J. (ed.), Cine de animación japonés (pp. 125-141). San Sebastián: Semana de Cine Fantástico y de Terror de San Sebastián.

Little Witch Academia Project (2013). Message from Otsuka Masahiko. Retrieved 15 October 2016 from https://www.kickstarter.com/projects/1311401276/little-witch-academia-2/posts/535690

Mann, F., Mahnke, R. \& Hess, T., (2012). Find Your Niches: A Guide for Managing Intermedia Effects Among Content Distribution Channels. International Journal of Media Management, 14(4), 251-278.

Mollick, E., (2014). The Dynamics Of Crowdfunding: An Exploratory Study. Journal of Business Venturing, 29(1), 1-16.

Montero Plata, L. (2012). El mundo invisible de Hayao Miyazaki [The Invisible World of Hayao Miyazaki]. Palma de Mallorca: Dolmen.

Mōri, Y. (2006). Subcultural unconsciousness in Japan: the war and Japanese contemporary artists. In Allen, M. y Sakamoto, R., (eds.) Popular culture, globalization and Japan (pp. 174-191). New York: Routledge. 
Mōri, Y., (2011). The Pitfal Facing the Cool Japan Project: The Transnational Development of the Anime Industry under the Condition of Post-Fordism. International Journal of Japanese Sociology, 20(1), 30-42.

Nichtlustig die Serie Project (2016). Nichtlustig die Serie. Retrieved 28 December 2016, from https://www.kickstarter.com/projects/nichtlustig/nichtlustig-dieserie

Poitras, G. (2008). Contemporary Anime in Japanese Pop Culture. In MacWilliams, M. W. (ed.) Japanese Visual Culture. Explorations in the World of Manga and Anime (pp. 48-67). New York: M.E. Sharpe, Inc.

Salo, J., Lankinen, M. Mäntymäki, M., (2013). The Use of Social Media for Artist Marketing: Music Industry Perspectives and Consumer Motivations. International Journal on Media Management, 15(1), 23-41.

Scott, S., (2015). The Moral Economy of Crowdfunding and the Transformative Capacity of Fan-ancing. New Media \& Society, 17(2): 167-182.

Sito, T. (2006). Drawing The Line: The Untold Story Of The Animation Unions From Bosko To Bart Simpson. Lexington: University Press of Kentucky.

Steinberg, M. (2006). Immobile Sections and Trans-Series Movement: Astroboy and the Emergence of Anime. Animation: An Interdisciplinary Journal, 1(2), 190-206.

Steinberg, M. (2009). Anytime, Anywhere Tetsuwan Atomu Stickers and the Emergence of Character Merchandising. Theory, Culture \& Society, 26(2-3), 113-138.

Steinberg, M. (2012). Anime's Media Mix: Franchising Toys and Characters in Japan. Minneapolis: University of Minnesota Press.

Steinberg, M. (2013). Copying Atomu. Mechademia, 8(1), 127-136. 
The Cyanide \& Happiness Show Project (2012). The Cyanide \& Happiness Show. $\quad 28$ Retrieved December 2016 , from https://www.kickstarter.com/projects/explosm/the-cyanide-and-happiness-show/updates The Goon Project (2012). "The Goon" Movie... let's KICKSTART this $\begin{array}{lllll}\text { sucker!!! } & \text { Retrieved } & 28 & \text { December } & \text { 2016, }\end{array}$ https://www.kickstarter.com/projects/624061548/the-goon-movie-lets-kickstart-thissucker/updates

Thorn, M. (2004). Girls and Women Getting Out of Hand: The Pleasure and Politics of Japan's Amateur Comics Community. In Kelly, W. W. (ed.) Fanning the Flames: Fans and Consumer Culture in Contemporary Japan (pp. 169-187). New York: State University of New York Press.

Tobin, J. (2004). Pikachu's Global Adventure: the Rise and Fall of Pokémon. Durham: Duke University Press.

Under the Dog Project (2014). Under the Dog Campaign. Retrieved 15 October 2016, from https://www.kickstarter.com/projects/774031583/under-the-dog

WAFKU Project (2014). WAFKU: The Animated Series. Retrieved 28 December 2016, from https://www.kickstarter.com/projects/ankama/wakfu-theanimated-series?lang=es

Yano, C. (2013) Pink Globalization: Hello Kitty's trek across the Pacific. Durham: Duke University Press. 


\section{Funding information}

This work was supported by Ministerio de Economía y Competitividad del Gobierno de España for the research project El sistema de investigación en España sobre prácticas sociales de comunicación. Mapa de proyectos, grupos, líneas, objetos de estudio y métodos under Grant number CSO2013-47933-C4-4-P code 14I275.01/1; by the Universitat Jaume I for the research project La crisis de lo real: la representación documental e informativa en el entorno de la crisis financiera global,

under Grant number P1·1A2014-05; by Comunitat Valenciana through the scholarship Programa VALi+D, under grants ACIF/2015/162 and BEFPI/2016/055. 